Shirley Barnes

has been director of her own recreation planning and community development consultancy for the last 11 years, is a member of the International Committee on the Sociology of Leisure (ISA) and the IFPRA, and a Fellow of Parks and Leisure Australia. Shirley served many years with state and local government on issues related to recreation and sport throughout WA. She has been a sessional lecturer and tutor in leisure and ageing for the Edith Cowan University, and has made many conference presentations on issues related to rural areas, local government and the elderly, based particularly on applied research. She is also a voluntary health consumer representative, working with GPs and nurses.

Keywords:

seniors, leisure, lifestyle, markets, facilities, services and programming
Shirley Barnes

Director

Shirley Barnes \& Associates

PO Box 1021

Cloverdale, WA 6985

Australia

Tel: +61 892779538

Fax: +61 892779538

E-mail: sbarnes@iinet.net.au

\section{Working with, and for, our seniors: Is local government leisure provision keeping up with the ageing population?}

Shirley Barnes

Received (in revised form): 21 January 2001

\begin{abstract}
It is a fact that the population throughout the world is ageing rapidly, but there is continuing emphasis on youth, strength, peak fitness and magnificent facilities for elite sportsmen and women, as witnessed in the 2000 Olympic Games in Sydney and the increased funding in Australia for elite sportspeople as a result of that successful event. Currently, an 'older person' is considered to be someone over 60 years of age, and there is an enormous available, and potential, pool of cash-rich and time-rich consumers which appears to receive little consideration. This paper discusses whether developers and managers of facilities, services and programmes particularly in local government, but also in private enterprise - are aware of the market and providing sufficient real resources for older members of society. Australia is used as a case study, but some worldwide trends are also examined.
\end{abstract}

\section{INTRODUCTION}

In a recent article, 'Healthy, wealthy and wise', by Cathy O'Leary, in the daily newspaper The West Australian (11 July 2001), the executive director of one of the largest aged care groups in the state of Western Australia (WA) and the Council on Ageing executive director agreed that in the future, illness and disability will only be an issue for most seniors in the last few months of their lives as a result of better health, medical and lifestyle practices overall; 'babyboomers' will not grow old in the same way that their forebears did and their lifelong expectations of service and choice (which have been made possible through their better education and generally increased purchasing power) will continue into old age. ${ }^{1}$

Currently, this group of seniors in Australia hold about a third of the voting power, but in 20 years' time they will be able to exert a huge amount of political muscle because they will form about 50 per cent of the voting population. ${ }^{2}$ This fact is related to a worldwide trend as reported in the year 2000 by the United Nations:

One out of every ten persons is now 60 years or above; by 2050 , one out of every five will be 60 years or older; and by 


\section{0, one out of three persons will be 60 years or older... Such a rapid, large and ubiquitous growth has never been seen in the history of civilization. ${ }^{3}$}

More specifically, in New Zealand, June 2000 statistics show that 12 per cent of the total population was more than 65 years of age, with an estimated annual increase of 3 per cent per year; ${ }^{4}$ in the USA in the year 2000, one in every eight persons was aged over 65 years - 12 per cent higher than in $1990 ;{ }^{5}$ while between 1981 and 1998 in Canada, the numbers of those aged 65 and over grew by almost 60 per cent - more than twice as fast as the overall population - resulting in the fact that one in every ten is now a senior, with projections that by 2021 seniors will comprise 18 per cent of the total population, and by 2041 the percentage is expected to be 23 per cent. ${ }^{6}$ Most of this substantial growth is from 'improving survivor' rates since the world wars as a result of better health, medical and economic environments, with a greater depth and diversity added by improved standards for indigenous and immigrant ethnic groups.

A further fact stated by the United Nations ${ }^{7}$ is that throughout the world the older population itself is ageing, with those over 80 years the fastest growing segment - currently 11 per cent of the 60 -plus age group, growing to 19 per cent by 2050 . Of older persons, 55 per cent are women, with that figure rising to 65 per cent among the older old. This growth in the older sector of the world population will have an enormous and far-reaching impact on the old-age dependency ratio for the general population, with a doubling in developed regions and tripling in less developed regions between 2000 and 2050, and it is predicted that it will continue well into the coming centuries.

These older persons will have a rich, combined experience to share with younger members of society - of history, skills and abilities, human stories, humour, compassion and goodwill. And perhaps some younger people may think it odd, but they will also have a vision for the future.

However, this group will be even more diverse than in previous years. On the one hand, there will be the asset-rich, with a large disposable income - the superannuated and those who have managed to attain high financial stability through well-paid jobs. On the other hand, there will be seniors who were not part of the longterm workforce or did not attain financial security for a variety of reasons, including corporate disasters; lack of sufficient work skills; redundancy in later years when it is more difficult to find another job; either a permanent or late-occurring disability; single parents who have had to make a fresh start after a partnership break-up which often impacts on their financial status; women joining the workforce after their children have grown up - often taking casual and/or part-time jobs; ethnicity; a change of career/s; financial mismanagement; and just plain 'unemployability'. 
Statistical considerations
The question then arises as to whether in Australia the community and the various levels of government are currently planning and developing sufficient infrastructure so that seniors of all ages and capabilities are able to maintain a pleasing, meaningful lifestyle in the foreseeable future.

Some statistics should be considered.

- Australia has nearly 3 million seniors aged 60 years and over - an average 16 per cent of the current population. ${ }^{8}$ (South Australia (SA) has the highest proportion with 18.2 per cent, Tasmania follows with 16.8 per cent, then New South Wales (NSW) 16.6 per cent, Victoria 16.5 per cent, Queensland 14.8 per cent, WA 14.2 per cent and Northern Territories (NT) with 5.2 per cent.)

- In the year 2001, it is estimated that 12 per cent of the total Australian population was more than 65 years of age, expected to rise to at least 18 per cent by the year 2021 (with some sources quoting up to 25 per cent). ${ }^{9}$ This enormous increase arises from three basic facts: the number of 'baby-boomers' born between 1947 and 1955 - who have now progressed to the ranks of the seniors, the accelerated immigration of young people until the 1970s who are now among this group, and a declining birth rate in Australia since the 1960s. ${ }^{10}$

- The projected annual growth rate of the Australian aged population between 1986 and 2031 is 2.4 per cent. It is estimated that of a population of approximately 20 million, 4.8 million will be then be aged 65 years and over. ${ }^{11}$

- Currently, there are 1,700,000 people over the age of 70 living in Australia. ${ }^{12}$

- The life expectancy at birth for indigenous people in Australia is nearly 20 years less than for non-indigenous people respectively, 57 years for men and 64 years for women, compared with 75 and 81 years - as a result of a past lack of appropriate, accessible health education; remote and isolated rural living in many instances; and ongoing social factors such as unemployment and drug and alcohol abuse. ${ }^{13}$ (These problems are now being addressed, but it will be many years before the survivor rates converge.)

- Cultural diversity among seniors is an increasingly important issue, with a national average of 30 per cent born overseas highest in the Australian Capital Territories (ACT) and WA (40.6 per cent and 40.3 per cent respectively) followed by Victoria, S.A., the NT, NSW and Queensland, with Tasmania the lowest at 18.1 per cent. ${ }^{14}$

To be considered in this context are some other factors.

- The average Australian family size is shrinking, with singleadult/two-person households becoming the norm. Nationally, more than 24 per cent of households are classed as single-person households. ${ }^{15}$ 
- Australians are living longer, retiring earlier and are healthier in their senior years than ever before. ${ }^{16}$

- Because of superannuation benefits, many can also expect to be more financially secure than their parents.

- The elderly have an important role in the economy through their expenditure and consumption, as well as through productive work in paid and voluntary employment. In WA alone, about 4 per cent of the total workforce are seniors, and one in eight are still employed or looking for full-time or parttime work, while approximately one in four is a volunteer providing community service through meals on wheels, home help, schools, hospitals and sporting associations. Incidentally, surveys also show most will spend their money rather than leave it to their children. ${ }^{17}$

- Many older people now choose to remain in their own homes especially if sufficient care services are accessible to them or a carer is available, such as a spouse, partner or family member (less of an option for females). ${ }^{18}$

- Because there are insufficient beds available, older people are being encouraged by the government to remain in their own homes rather than enter institutions, and there will be both economic and social impacts as this trend is expected to increase — an escalating need for home medical, health and social services; an increased need for accessible transport for the less mobile and disabled persons; and a rising need for more passive leisure facilities and services for older persons.

- Overall, older females cope better with daily living than older males because they generally have more varied interests and socialise more easily.

How are parks and recreation professionals, while recognising that everybody is approaching this future — but hopefully also as caring, considerate individuals - proposing to deal with this complex community of senior citizens?

\section{Problems of longevity}

\section{MAJOR ISSUES}

Because seniors are now, and in the future will be, living longer as a result of increasingly better health practices, many seek to remain in their own homes until they are in their 70s and 80s if they do not require a high level of care. However, because there is so much emphasis on the welfare aspects of people's lives and most government resources are linked directly to such matters transport to medical appointments and perhaps some limited shopping - there is a very real division between those seniors who are still able to participate in community life because of their personal situation and those who have no possibility of doing so without community assistance.

Often friends and/or neighbours will look out for a local senior who remains in their own home, or an individual is able to exist 
with meals on wheels deliveries and perhaps a volunteer to assist them with shopping. Generally, however, resources are severely limited for leisure opportunities unless they have a partner, family member or friend who drives a car and is able to ferry them around. If their sight or hearing is no longer acute and they are relatively housebound there may be limits to reading, TV watching or computer access, with the opportunity to socialise almost nonexistent.

Others are unable to remain within the general community because they can no longer cope with the gardening, heavy housework or the preparation of meals, and many seniors these days are greatly concerned with their personal safety, as they believe they are targeted by burglars and 'muggers'. Therefore, if a reasonable level of care or assistance is not available, they are compelled to give up their independence. (There are some voluntary and government groups which provide wonderful assistance for older people, but with strictly limited and monitored resources, and in some instances they are unable to respond because the potential client does not 'fit the criteria'. This will be referred to again later in the paper.)

Regardless of their financial situation, older people generally worry about a loss of control over their lives, and this is probably the most overriding issue of all.

Many believe that they 'cannot keep up' with modern society world communities are transient and different from those previously known to many older people; it appears that a different set of values and morals now holds sway; modern technology is

\section{Range of concerns} alienating many; 'old age' brings a whole new set of problems, perhaps in health or human relationships. All have a major effect on their lives.

Specific concerns involved may vary with different people:

- knowing where to access required information;

- telephone systems which mean that they cannot talk to 'real' people;

— 'surfing the Net' as opposed to not wanting anything to do with computers;

— personal safety when out walking — fear of falling or being mugged, as well as no one to walk with;

- easy access to public transport;

- feeling safe in their own homes - either for health reasons or fear of invasion;

- caring for partners, siblings or parents over long periods;

- losing partners - no one to talk to/go out with, and perhaps the loss of the car driver;

- knowing where to socialise with compatible others;

- government-provided residences in areas which are isolated or cut off from past and potential sources of socialisation;

— being 'housebound' — physically, mentally or emotionally — 
because family do not visit or take them out, they do not have access to private or public transport, they have a disability, and/ or peer group members have moved to institutions or died;

- being obliged to enter a nursing home because of the level of physical care required in later life and generally a lack of suitable and available home help - sometimes with the additional trauma of being separated from a long-time partner because there are no double rooms available.

While some of the above elements may not appear to be directly related to leisure and recreation, close consideration would show that they all have a major impact on seniors and their choice of options for leisure and well-being. If individuals feel they are no longer able to choose whether to remain in their own home; walk in safety; visit the shopping centre, library, theatre, community centre or beach; participate in classes of interest or outings with friends; or just remain a useful member of society, how is it possible to maintain a sense of self-worth, challenge and pleasure in living? In fact, such circumstances would alter one's specific view of the world.

It has been known for at least a decade that the overall population in Australia, and the world generally, is ageing but has society ignored the fact that changes should occur in planning for recreation options and that the focus of the market is changing? Has society really made an effort to consult with the complex group of seniors and understand their needs, and, in the context of existing and dwindling resources, made determined progress towards providing adequate and reasonable options for their leisure time?

The author believes that one of the major community challenges - both currently and in the near future - is to work collaboratively with the ageing society so as to provide services and programmes which genuinely meet their needs and desires. Service providers - whether governmental or non-governmental - have to be committed to working with senior citizens and encouraging them to remain active both physically and mentally, not only for their own individual benefit but for society as a whole. If Society does not do this, everyone will be the poorer.

In April 2001, at the World Leisure Conference in Shanghai, China, where the theme was 'Social Development, Leisure and the Older Person', it was interesting to note that of the ten countries represented, no government had a definite handle on policies which would provide overall benefits for their diverse populations of seniors. While some were coping reasonably adequately with the welfare aspects of seniors' lives, their leisure opportunities were generally ignored. It appears that only a few forward-thinking people and community groups, some very small sections of any government and a minority of academic institutions are wrestling with the increasingly visible leisure issues now relative to an ageing community. 
Research requirements
During the conference, it became apparent that:

- research makes a direct contribution to providing direction for quality of life for the elderly by thorough investigation of their needs so that practical strategies may be implemented to assist maintenance of a positive community profile;

- an cohesive approach is required with integrated policies for the elderly, rather than a 'piecemeal' approach which addresses specifically only accommodation, economic or health aspects of their lives;

- prolific research on ageing is being undertaken in the USA, particularly by academics, but it does not appear to have a high profile elsewhere;

- qualitative (one-to-one) and comparative studies are required as well as quantitative information, to gain a 'human assessment' of individual lives, especially for those who have difficulty in completing forms because of an educational or cultural background or are 'less visible' in their daily lives;

- few studies are currently being undertaken on intergenerational, rural and cultural issues for seniors or concerning the institutionalised frail;

- training for those working with the elderly should be a high priority - especially concerning legal issues and standards setting - so that each individual is assured of the comfort, respect and due care which should be their right, regardless of whether they are able to judge that for themselves;

- recreation and community centres are the main venues for exercise, socialisation and rehabilitation/therapy - but it is questioned whether the environment is attractive enough and what is happening in seniors' own homes for those unable to venture out;

- cultural and educational activities such as concerts, the theatre, book clubs and computer access are required, as well as sportsoriented or more active leisure pursuits, to maintain mental fitness and pleasure;

- a greater exchange of information is required between countries on research findings;

- rehabilitation is a huge issue still to be addressed - particularly regarding assessment and techniques used to provide activities for seniors, especially in leisure and recreation for quality of life; sports administration, which is not an appropriate avenue for assessment of the elderly; and nursing homes, which are coming under the umbrella of recreation departments in some countries, such as the USA and Australia in some states.

In other research, ${ }^{19}$ it appears that older persons in Australia, New Zealand, Canada and the USA at least have basically the same concerns, apart from financial and health issues.

- An increasing diversity of ethnic backgrounds and cultural influences among older people in these countries is arising as the 
life expectancy of indigenous people rises through better health and social practices, and older immigrants are now numbered in their ranks. (These differences are expected to decrease in the future as the generations integrate.)

- There is an apprehension that they will be the victim of crimes such as burglary, theft and 'mugging', although statistics show that this is not the reality.

- Transport and medical services are limited in many instances, particularly in rural regions, so seniors must relocate to urban areas to access appropriate accommodation and health services.

- Most seniors prefer to remain in their own homes and the majority are homeowners in countries such as Australia, New Zealand, the USA and Canada.

- A percentage of older persons are still employed at least parttime and/or volunteer their services on a limited basis to a wide variety of organisations on a weekly basis - even when over 80 years of age.

The majority of older persons believe that they are reasonably fit and healthy.

\section{ADDRESSING THE ISSUES}

There are no easy answers to this accelerating problem, but rather this paper is trying to spark some debate and consideration of the issues, so that a multitude of minds are able to generate and apply a diversity of ideas.

While considering some of the processes now being used to address these issues on a collaborative basis, the following came to mind. There are others, but these are useful examples of where to find assistance with planning and development for people who are unable to resource their own research or do not have their own sources of information.

On the policy front in Western Australia, there is the Office of

Existing positive examples
Seniors' Interests, which defines its concept of positive ageing as 'every person leading a life as fulfilling as possible in their particular circumstances' and recognises that individuals have different measures of what positive ageing is for them. It also affirms that the concept needs to be embraced by everybody - not just seniors - and points out that ageing positively depends to some extent on lifestyle decisions made in younger years. Other states have similar government departments for the acquisition of information, and there is always the Australian Bureau of Statistics (or similar national organisations) which can supply the background for planning by providing demographical statistics including the age and gender balance, population density and economic status within a particular community.

For policy research across a range of subjects which will assist policy development for seniors, there is the Positive Ageing Foundation in Australia, which has a vision of 'creating agefriendly communities' and has just celebrated its first national 
Increasing 'aged' market birthday. In WA, currently diverse studies are in progress, including travel and tourism for seniors and the attitude of seniors towards the state's symphony orchestra. It also undertakes practical programmes such as:

- assisting with advice and coordination efforts to upgrade the images, services and facilities at senior citizens' centres;

- scheduling 'walk ball' sessions in community centres - a mobility/coordination activity demonstrated by a senior citizen to encourage others to exercise;

- coordinating an in-house computer centre with sponsorship from a commercial organisation, to enable seniors to learn from other seniors;

- a new programme to link the various generations within the community;

- the establishment of partnerships in the Asia Pacific region in countries such as Indonesia and China - assisting them to develop training in aged care and the provision of better services to more older people within this region for social, political and economical reasons;

- the operation of a volunteer programme for a range of duties which takes advantage of existing skills and abilities within the seniors' ranks, provides some training in new skills and enables the organisation to operate on a wider front than would otherwise be possible with a limited economic basis;

- partnerships with a number of not-for-profit, community and educational organisations to extend their capacity to share the interests of older people;

- the development of a corporate partners programme to encourage and foster the participation of the business sector - with the mutual advantages of an injection of financial or in-kind resources for the seniors and a wider marketing opportunity and higher profile for the commercial organisation.

Furthermore, of interest to all service providers in Australia should be a report commissioned by the federal government and released in March $2001 .^{20}$ Among the highlights within this study, 'Access Economics' forecasts:

- a revolution in Australian spending habits fuelled by the growing significance of the so-called 'grey dollar' - although currently the GST factor (an overall tax applied to goods and services by the federal government at the beginning of the 2000/ 2001 financial year, supposedly so that other 'hidden' taxes would be deleted) appears to be having an influence on people's willingness to part with their money;

- that changes will be required to the thinking and marketing processes of manufacturers, wholesalers, retailers and leisure 


\section{Programming services} directions providers if they are to survive - particularly in connection with those aged 55 years and over in the next decade;

- that bookshops, garden centres, DIY outlets, small cars, holidays, telephone communication with family and friends and some mild, recreational gambling habits will become the preferred options for leisure, based on the current recreation trends for older persons;

- fast-food outlets, restaurants, sports and fashion shops, pubs, nightclubs and perhaps video and CD shops will probably become less important as the younger sections of the population join the ever-growing ranks of the ageing.

There are also another few 'straws in the wind' which indicate that at least some Australians are aware that there will be a programming and services problem, and that this lack of planning for seniors needs to be redressed now. This includes the Seniors' Recreation Council of WA and its programmes, and the Australian Sports Commission and its joint efforts with the Brisbane City Council and also its 'Never Too Late' information.

It must be said, too, that some facility managers in local government authorities are currently scheduling activities for seniors, particularly during the quieter times of the day when younger people are generally at school or work. Examples are:

- exercise groups specifically for older persons (perhaps with back, knee or arthritis problems);

- t'ai chi and yoga sessions which provide gentle physical and breathing exercise;

- swimming classes and aquarobics;

- bocce and bowling sessions;

- the coordination of walking groups with a social 'cuppa' afterwards;

- computer and art/craft sessions specifically for seniors;

- film days with a socialisation component;

- educational classes which are part of the University of the Third Age or similarly oriented towards advanced learning without examinations.

It should be recognised that many of the people who access this information and enjoy these recreations are among those who are generally well informed and mobile, and often are already involved in a wide range of other activities which may include canoeing, archery, ballroom dancing, boot scooting and bike riding. At the other extreme of the activity scale are those frail aged or disabled people who participate in day-care programmes, which provide them with an opportunity to socialise, exercise and enjoy structured leisure activities because they are also provided with transport and assistance.

However, what is available for the majority of seniors - 
especially those who are not so aware, are perhaps less mobile, without family or peer group, not identified as requiring special assistance and/or who do not have access to public transport?

It appears that there is little knowledge of the home situation of many Australians; only a very small percentage of research is based on institutionalised leisure time or seniors in country towns - as may be seen when seeking relevant information; indigenous people and those from other cultures require different approaches, and there is generally little understanding of the extent of the issues involved; and senior males continue to be depressed, to the extent of taking their own lives in some instances.

Some current projects are focused on these older and less aware/ less mobile seniors in WA in an effort to provide socialisation and a change of scenery.

- 'Telecross', which is funded by the WA Health Department's Home and Community Care Programme, is run by Australian Red Cross staff and volunteers, who telephone one or more elderly or disabled persons living alone at a set time every day. The callers and the person at home are matched by area, age, sex and interests, and include volunteers 80 years of age and older.

- Interaction with children and resident dogs and cats in a leafy environment at nursing homes - although there is also usually a problem for the pets, which gain weight from eating too many snacks.

- Volunteers offering a type of 'make-a-wish' fulfilment for nursing home residents in a regional centre, including rides on motorbikes, driving a racing car or dressing up as Father Christmas.

- A community visitors scheme in another regional city, which provides socially isolated residents in aged care facilities with a volunteer visitor on a weekly basis; the volunteer may also take them on outings. It has been running since 1993, has now been taken over by a private organisation and provides great pleasure on both sides.

\section{TAKING STEPS}

When developing and maintaining communities, there is a need to

\section{Planning with seniors} consider some of the following issues, and organise work accordingly.

- Seniors need to be included in the community recreation planning - as well as the local football and cricket clubs, the schools and the youth group.

- When planning accommodation for seniors in communities, sites need to be chosen carefully: small complexes are ideal and increasingly large 'grey ghettos' are not popular with the stakeholders - partly because many older people wish to 
remain within the general community rather than be confined to an area which may become a target for burglars and vandals. They should be centrally located, not on the outskirts of a community, so that the seniors are part of the community and may observe the daily activities of the community, even if they are not able to actively participate; peer group members, friends, home visiting staff and mobile libraries have ready access to seniors at home; and if mobile, seniors have some independence and are able to travel on foot, or with wheelchair or walking frame, to points of interest including shops, library, the community centre, and the football or bowling club, especially if they have been long-time members of the latter.

- Safe walking routes are essential, not only for seniors, but for parents with prams and disabled persons, and these should be part of every park maintenance and townscape schedule. They should feature level, even paths; no overhanging branches or prolific planting of bushes and trees close to paths and seating areas to ensure that debris underfoot and 'mugging' are not concerns; aesthetic value, and practical linkages to facilities should be considered when developing pedestrian routes; stable seating close to paths or with hard-surfaced approaches and adjacent hard standing at regular intervals; and maintenance as a regular practice.

- Access to public transport is another essential. For those who exert some control over the use of community buses, a prime consideration should be to ensure that senior citizens and disabled persons are linked to community facilities on a regular basis, particularly if there is a lack of other public transport. This should include the local library — preferably as an additional service to home delivery of books for the housebound - so that the less mobile are able to socialise with others in a relaxed environment outside their homes.

- Educational classes (including learning how to use computers, which can open up the whole world for those with restricted mobility) need to be scheduled at appropriate times to challenge seniors mentally - for pleasure, education and the acquisition of new skills - in conjunction with active recreation sessions for their physical well-being. These sessions need to be made accessible through transport provision, low cost and empathetic tutors.

- Seniors with an indigenous or non-European background, while they are hopefully integrated into the Australian community, may have learnt English as a second language when young adults, and retain centuries of tradition in their cultural memory. These indigenous people and migrants are an integral part of Australian society and while it is now being recognised that they have enriched, and will continue to enrich, the Australian sense of self-identity, it is also necessary to acknowledge that currently there are some differences in cultural 
Implications for leisure practices, particularly for older residents. As people age, they often prefer a language and experiences from their early years and planners must ensure that these differences do not become a channel for increasing isolation as people age - rather, seniors should be able to live in a society which welcomes the depth of cultural experience they provide through interactive community experiences, especially with younger people. (It is to be expected that younger people - the X and Y generations - with such roots will often be distinguishable only by their colouring or facial features, so this issue may not have such a high profile in later years.)

- There is a need to lobby all levels of government, politicians and other decision makers for additional resources in nursing homes for leisure programmes. Over a decade ago, the author was involved in a project in WA which encouraged aged-care staff to provide exercise and stimulation for frail residents through musical and nostalgia games, chair-bound activities and interesting craftwork. Personnel at that time had sufficient resources to provide a range of leisure opportunities for their enclosed communities. Currently, with the best will in the world the staff are generally unable to provide more than reading aloud the newspaper, word games, occasional cooking classes, concerts and some outings, as a result of an increasingly full occupation of available beds; economic restrictions which have led to staff cutbacks; and a rising level of dependency as residents are generally frailer and in the upper age bracket when they now enter the nursing home. The staff do provide cheery words, great patience in sometimes meaningless conversations, hugs and physical comfort for the confused and lonely, and a 'sense of place' for most of their charges. But they are often unable to spend precious time taking wheelchair-bound residents to a local park for a small picnic, to sit in the sun chatting, to put nail polish on the hands of an elderly lady or enjoy another's photo albums and tales of her travels, or to listen to an old man's reminiscences of his youth and write them down for posterity.

\section{CONCLUSION}

Currently, there is only minimal interest in the provision of recreation opportunities for seniors. However, the implications of the rapidly increasing proportion of older persons for the leisure industry - and in particular for local government, commercial organisations and other operators of current public facilities and services - are enormous.

As examples, the need for elite fitness clubs and adventure parks will lessen as the requirement increases for more facilities and programmes offering greater opportunities for 'togetherness' and socialisation; community groups will find it more difficult to attract and retain volunteers as old age and decreased mobility overtake 


\section{Partnerships required}

many of the current, more willing workers; and football fields and young children's playgrounds will attract fewer users as book clubs, libraries, bocce and safe travel become prime leisure options.

And, too, the 'mind-set' for leisure programming must be altered to accommodate the needs of older persons rather than aimed specifically and continually at the younger market, which is rapidly becoming smaller.

Finally, as leisure professionals, community development personnel and park managers, there are some measures that can be addressed immediately without a major use of resources, and planners must 'begin to make a difference'. These professionals must be prepared to assist others who are currently endeavouring to deal with this rapidly advancing 'new age'.

But specifically, there is a need for the desire to assist seniors and a commitment to involve them in the planning and development of infrastructure and programmes, in a true partnership.

\section{References}

1. Office of Seniors Interests, information supplied in brochures and pamphlets, including unpublished tables from the 1996 Australian Census of Population and Housing by the ABS, Canberra, commissioned by the Office of Seniors Interests. Topic sheets 1-3 Western Australia's Seniors, Nov. 1999-Feb. 2000 Office of Seniors Interests, The Government of Western Australia (May Holman Centre, 4th Floor, 32 St Georges Terrace, Perth Western Australia, 6000; www.osi.wa.gov.au)

2. Population Division, 'The ageing of the world's population', Department of Economic and Social Affairs, Gateway to Social Policy and Development: Ageing, United Nations Secretariat, May 2000; www.un.org/esa/socdev/ageing/agewpop.

3. Ibid.

4. 'Positive ageing in New Zealand: Diversity, participation and change.' Status Report 2001, Ministry of Social Development, Wellington, New Zealand.

5. 'Profile of age characteristics for the United States: 2000 and 1990 (based on 2000 and 1990 Census data)', US Administration on Aging.

6. Statistical Snapshots: A Growing Population. Canada's Seniors, Statistics Canada for the Division of Aging and Seniors, Health Canada, May 2000; www.hc_sc.gc.ca/seniorsaines/factoids/en.

7. UN Secretariat, ref. 2 above.

8. Census: 1996 Population Statistics, Australian Bureau of Statistics, 1996; www.abs.gov.au.

9. Ibid.

10. Barnes, S. L., unpublished research, 1997/1998.

11. ABS, ref. 8 above.

12. Office of Seniors Interests, ref. 1 above; ABS, ref. 8 above.

13. Office of Seniors Interests, ref. 1 above.

14. ABS, ref 8 above; Barnes, ref 10 above; Barnes, S. L., Reports written for various shire councils in Western Australia, 1998-2000, unpublished.

15. Office of Seniors Interests, ref. 1 above.

16. Barnes, ref. 10 above.

17. Ibid.

18. Ibid.

19. Ibid.

20. Australian Federal Government (2001) 'Population ageing and the economy', Access Economics for the Commonwealth Department of Health and Aged Care, www.health.gov.au/acc/ofoa/research_and_data/access_economy.htm. 